\title{
BMJ open Respiratory symptoms and peripheral airways disease in a cross-sectional study on a random population sample
}

\author{
Jan Yngve Olofson, ${ }^{1}$ Birgitta Houltz, ${ }^{2}$ Maria Nilsson Tengelin, ${ }^{3}$ Björn Bake ${ }^{1}$
}

To cite: Olofson JY, Houltz B, Nilsson Tengelin M, et al. Respiratory symptoms and peripheral airways disease in a cross-sectional study on a random population sample. BMJ Open 2012;2:e001488. doi:10.1136/bmjopen-2012001488

- Prepublication history and additional table for this paper are available online. To view these files please visit the journal online (http://dx.doi. org/10.1136/bmjopen-2012001488).

Received 24 May 2012 Accepted 25 October 2012

This final article is available for use under the terms of the Creative Commons Attribution Non-Commercial 2.0 Licence; see http://bmjopen.bmj.com

\footnotetext{
${ }^{1}$ Department of Respiratory Medicine and Allergology, Institute of Medicine, Sahlgrenska Academy at University of Gothenburg, Gothenburg, Sweden ${ }^{2}$ Clinical Physiology, Sahlgrenska University Hospital, Östra, Institute of Medicine, Sahlgrenska Academy at University of Gothenburg, Gothenburg, Sweden

${ }^{3}$ Department of Measurement Technology, SP Swedish Technical Research Institute, Borås, Sweden
}

Correspondence to Dr Jan Yngve Olofson; jan.olofson@lungall.gu.se

\section{ABSTRACT}

Objectives: Respiratory symptoms are associated with spirometry results but more strongly with smoking history, suggesting that alterations in the lung other than those revealed by spirometry contribute to cause symptoms. Smoking may cause obstruction of peripheral airways that is poorly detected by spirometry. The slope of phase III of the single-breath nitrogen $\left(\mathrm{N}_{2}\right)$ test detects smoking-induced alterations in smokers before spirometry is impaired. The aim of the present investigation was to study the association between respiratory symptoms and the slope of phase III adjusting for spirometry results and smoking history. Design: Single-centre retrospective cross-sectional study.

Setting: University hospital in Gothenburg, Sweden. Participants: A random population sample of 430 elderly men.

Methods: The presence of seven different respiratory symptoms were analysed by a multiple logistic regression model in relation to spirometry results, smoking history (pack-years) and the slope of phase III in a population sample of 430 elderly men, age span 50-67 years. Furthermore, smoking normalised values of the slope of phase III were calculated and differences between subjects reporting/not reporting symptoms were tested.

Results: The presence of some cough symptoms was significantly associated with a steep slope of phase III also when adjusting for spirometry results and smoking history. Furthermore, smoking normalised slope of phase III was significantly steeper among subjects with cough symptoms compared to those without cough symptoms.

Conclusions: Cough symptoms may be an effect of abnormalities in peripheral airways at least among elderly men.

\section{INTRODUCTION}

The ability of respiratory symptoms to predict chronic obstructive pulmonary disease (COPD), that is, spirometric airflow limitation, has been found to vary greatly both in random and in non-random population studies, as exemplified by various reported sensitivities (54-92\%), specificities

\section{ARTICLE SUMMARY}

Article focus

- Respiratory symptoms are more strongly associated with smoking history than with spirometric results.

- Smoking results in obstruction of peripheral airways that is poorly detected by spirometry.

- Hypothesis: the obstruction of peripheral airways is related to respiratory symptoms.

Key messages

- Obstruction of peripheral airways, as assessed by the slope of phase III of the single-breath nitrogen $\left(\mathrm{N}_{2}\right)$ test, is associated with some cough symptoms independently of spirometric results and in addition to smoking history.

- Cough symptoms may predict obstruction of peripheral airways in addition to smoking history, the likelihood ratio being between 5.3 and 2.5 for the various cough symptoms.

Strengths and limitations of this study

- The study was performed on a random population sample investigated twice, 7 years apart.

- The study comprised men aged 50-67 years only.

(19-89\%), positive predictive values (30-92\%) and negative predictive values $(75-96 \%) .{ }^{1-9}$ The general impression is, however, that respiratory symptoms are rather poor predictors of airflow limitation/COPD. Thus, respiratory symptoms appear to be only weakly related to low spirometric results.

Smoking history has been shown to be a stronger predictor of COPD than respiratory symptoms, ${ }^{1}$ 3-5 7-10 suggesting that smokinginduced airway alterations cause respiratory symptoms without detectable airway obstruction by spirometry. The pathological processes in smokers and COPD begin in the peripheral airways $^{11} 12$ and spirometry is insensitive in detecting early obstruction in the peripheral airways. $^{13-15}$ Therefore, it appears conceivable that the obstruction of peripheral airways contributes to the origination of respiratory symptoms. 
The slope of phase III of the single-breath nitrogen $\left(\mathrm{N}_{2}\right)$ test (slope of phase III) is more sensitive than spirometry in detecting obstruction of peripheral airways in smokers. ${ }^{15-17}$ Respiratory symptoms in smokers may therefore be associated with an abnormal slope of phase III also when spirometry is within normal limits. Viegi et $a l^{18}$ found that the slope of phase III was significantly steeper among male smokers with respiratory symptoms than among those without symptoms. However, cigarette-smoking-associated large airway obstruction and possible effects of smoking other than small airway obstruction were not adjusted for.

The aim of the present analysis was to challenge the hypothesis that obstruction of peripheral airways is related to respiratory symptoms independently of spirometric results and smoking history. This was tested by analysing the relationship between reported respiratory symptoms and the slope of phase III when spirometry results and smoking history are adjusted for.

\section{MATERIAL AND METHODS}

The present analysis is based on materials obtained from population studies performed in 1973 and 1980. The study sample in 1973 consisted of 387 men born in 1913 and 220 men born in 1923, living in Gothenburg, Sweden. They were randomly selected from the national register comprising all residents of Sweden. ${ }^{19}$ In 1980, 303 of the men born in 1913 and 157 of the men born in 1923 attended for reinvestigation. On both occasions the examinations were performed during the same season of the year. Subjects lacking data on $\mathrm{FEV}_{1}$ (forced expiratory volume in $1 \mathrm{~s}$ ), VC (vital capacities), slope of phase III and smoking habits at both occasions were excluded from the study sample. Information on respiratory symptoms on both occasions of at least 10/12 questions should be available at both occasions otherwise the subjects were excluded. No subjects were excluded due to known disease. Accordingly, 30 subjects were excluded and a total of 430 men with data on respiratory symptoms (12 symptoms, see table 2), smoking habits, spirometry and the slope of phase III of the single-breath $\mathrm{N}_{2}$ test in both investigations, constitute the present material. ${ }^{20}$

All lung function measurements were performed by well-trained technicians and with the subjects in the sitting position and a nose clip applied. Spirometry was performed with a servospirometer (Model 150A, Med-Science Electronics, Ohio, USA) connected to a rapid UV-light recorder (Ultralette, ABEM, 5651, Stockholm, Sweden). Volumes and flows were corrected to body temperature pressure saturated (BTPS) condition. Calibrations of the equipment were performed regularly. Two satisfactory slow VC, one inspired and one expired, and three satisfactory forced VC measurements were performed by each subject. The largest $\mathrm{VC}$ and $\mathrm{FEV}_{1}$ were used in the analyses and $\mathrm{FEV}_{1} / \mathrm{VC}$ was calculated. $\mathrm{VC}$ and $\mathrm{FEV}_{1}$ were expressed in per cent of predicted normal (\%pred) using reference values according to Hedenström $e t a l .^{21}$

The single-breath $\mathrm{N}_{2}$ test was performed as described by Oxhöj $e t a l .{ }^{1622}$ At least two tests with satisfactory tracings were attempted for each subject with an interval between the tests of a minimum of 5 min. Tests with a difference of more than $10 \%$ between inspired and expired VC, were excluded. All tracings were coded and examined by one investigator, unaware of the identification and characteristics of the subjects. The slope of phase III was calculated as the increase of the nitrogen concentration from the point where $825 \mathrm{ml}$ (BTPS) had been expired from total lung capacity until the beginning of phase IV (closing point), divided by the corresponding expired volume. The slope of phase III was calculated as per cent nitrogen per litre (BTPS) and expressed in \%pred, using the reference values according to Sixt et $a l^{23}$ All lung function data, that is, the slope of phase III, VC, $\mathrm{FEV}_{1}$ and $\mathrm{FEV}_{1} / \mathrm{VC}$ are presented as the calculated mean value of the values obtained from the two investigations.

Respiratory symptoms were assessed using a translation of the questionnaire approved by the British Medical Research Council Committee on the aetiology of chronic bronchitis. ${ }^{16192425}$ A total of 12 questions on the symptoms: cough without or with expectoration, wheeze or squeaks and dyspnoea were evaluated (table 2). For each of the 12 symptoms, only subjects with the presence of that specific symptom on both investigations, or the absence of that symptom at both occasions, were included in the analysis and evaluated in relation to smoking habits, the slope of phase III of the single-breath $\mathrm{N}_{2}$ test and spirometry.

Smoking habits are estimated according to the classification reported in the second investigation. ${ }^{20}$ The subjects are characterised as follows: as non-smokers if they were never-smokers or had smoked less than $1 \mathrm{~g}$ tobacco a day for 6 months, exsmokers if they had stopped smoking 6 months or more before the second investigation, and considered smokers if they were smokers on the second occasion, had smoked at least $1 \mathrm{~g}$ tobacco a day for more than 6 months or had stopped smoking within the last 6 months. In the original database, the amount of tobacco consumed was registered in grams (g) per day (d) within given ranges, for example, 1-4 g/day, 5-15 g/day, etc. In the present estimation, we simplified the tobacco consumption accordingly; $1-4 \mathrm{~g} /$ day $=3 \mathrm{~g} /$ day, $5-14 \mathrm{~g} /$ day $=10 \mathrm{~g} /$ day, $\quad 15-24 \mathrm{~g} /$ day $=20 \mathrm{~g} /$ day and $\geq 25 \mathrm{~g} /$ day=25 g/day. One gram of tobacco is considered equivalent to one cigarette. On the basis of these approximations, the tobacco consumption was calculated in terms of pack-years. The mean consumption between the two investigations is used in the present analysis.

\section{Data analysis}

Statistica 7.0 (Statsoft, Inc, Tulsa, OK, USA) was used for the statistical analyses and a $p$ value $\leq 0.05$ was considered statistically significant in all analyses performed. 
In a multivariate logistic regression model of presence/absence of a given symptom, we included as independent variables the slope of phase III (\% pred), $\mathrm{FEV}_{1}$ (\% pred), $\mathrm{FEV}_{1} / \mathrm{VG}$ and pack-years. As the slope of phase III is highly right-skewed log-transformed values were used.

To further challenge the association between symptoms and the slope of phase III, smoking normalised values were calculated. Thus, the slope of phase III expressed in per cent of predicted normal values were regressed against smoking category and pack-years in the present material $(n=430)$ and smoking normalised predicted values were calculated. Observed values were then expressed as a percentage of the smoking normalised predicted values. The resulting average smoking normalised values were close to $100 \%$ for smokers as well as for non-smokers.

The ability of symptoms to predict an abnormal slope of phase III was also tested. Only smokers $\geq 20$ pack-years were included as there were relatively few subjects among light smokers and exsmokers with symptoms (see below). The limit 20 pack-years lie in between the median and the mean of tobacco consumption among smokers and exsmokers in the present material. Diagnostic characteristics of the relevant symptoms were calculated in terms of sensitivity, specificity, positive and negative predictive values and the likelihood ratio, and based on cut-offs defined by the 95 th or 5 th percentile of the predicted normal values among non-smokers without symptoms in the present material. The corresponding prediction of an abnormal $\mathrm{FEV}_{1} / \mathrm{VG}$ was included for comparison.

\section{RESULTS}

General characteristics of the study population are presented in table 1. Lung function deteriorates with smoking as expected, and the slope of phase III of the single-breath $\mathrm{N}_{2}$ test is increased in smokers as well as in exsmokers compared to non-smokers.

In general, respiratory symptoms were rare among non-smokers, more common in exsmokers and even more frequent in smokers, as shown in table 2. The total number of reported symptoms among non-smokers, exsmokers and smokers were 20, 125 and 282, respectively. The symptom 'wheeze or squeaks any time' was the most prevalent symptom in both smoking categories ( $59 \%$ and $31 \%$ in smokers and exsmokers, respectively), followed by the symptom 'wheeze or squeaks any time connected with a common cold' $(36 \%$ and $12 \%$ in smokers and exsmokers, respectively). Cough symptoms were substantially more common among the smokers $(9-28 \%)$ than among exsmokers $(2-7 \%)$ and was almost not reported at all among non-smokers.

To allow for a meaningful statistical analysis a specific symptom was analysed only if reported present by more than 10 smokers. Thus, nine symptoms were analysed further. Age was not associated with symptoms and was therefore not considered in further analysis. In a preliminary logistic model pack-years, $\mathrm{FEV}_{1}$ (\% pred), $\mathrm{FEV}_{1} / \mathrm{VC}$ and log slope of phase III (\%pred) were included as independent variables. Two symptoms 'cough usually day or night during winter' and 'cough and expectoration usually day or night during winter' were not significantly related to any lung function variable when adjusted for pack-years. The results of the preliminary model are given in the supplementary material (online supplementary table S3). In the final logistic model the seven symptoms and significant independent variables were included. The results are given in table 3 .

Pack-years were strongly associated with all the symptoms. The slope of phase III was significantly related to two of the cough symptoms whereas $\mathrm{FEV}_{1}$ was associated with the wheeze and dyspnoea symptoms and $\mathrm{FEV}_{1} / \mathrm{VC}$ to one cough symptom.

Table 4 gives smoking normalised values of the slope of phase III in relation to the cough symptoms being associated with the slope of phase III among exsmokers and smokers. The slope of phase III is significantly steeper among subjects reporting symptoms also after adjusting for smoking history.

Diagnostic characteristics are presented in table 5 . Cut-off values for the slope of phase III and the $\mathrm{FEV}_{1} / \mathrm{VG}$ ratio were $147 \%$ predicted normal and 0.65 ,

Table 1 General characteristics of the study population $(n=430)$ of $50-67$ years old men with a mean age of 60 years. Mean and range are presented

\begin{tabular}{|c|c|c|c|c|c|c|}
\hline & \multicolumn{2}{|c|}{ Non-smokers $n=96$} & \multicolumn{2}{|c|}{ Exsmokers $n=180$} & \multicolumn{2}{|c|}{ Smokers $n=154$} \\
\hline & Mean & Range & Mean & Range & Mean & Range \\
\hline Height (cm) & 175 & $159-191$ & 176 & $159-192$ & 174 & $158-192$ \\
\hline Weight (kg) & 79 & $59-115$ & 79 & $49-115$ & 75 & $55-101$ \\
\hline Pack-years & 0 & - & 16,1 & $0,2-51$ & 27,2 & $3-61$ \\
\hline VC (\%pred) & 95 & $67-129$ & 91 & $46-131$ & 88 & $60-131$ \\
\hline FEV $_{1}$ (\%pred) & 95 & $55-122$ & 89 & $32-121$ & 83 & $26-109$ \\
\hline $\mathrm{FEV}_{1} / \mathrm{VC}$ & 0,75 & $0,58-0,86$ & 0,72 & $0,35-0,86$ & 0,7 & $0,31-0,89$ \\
\hline Phase III (\%pred.)* & 92 & $-30-274$ & 136 & $19-744$ & 182 & $36-614$ \\
\hline
\end{tabular}


Table 2 Number of subjects, and the corresponding percentage, in relation to the presence of symptoms

\begin{tabular}{|c|c|c|c|c|c|c|c|c|c|c|c|c|}
\hline & \multicolumn{4}{|c|}{ Non-smokers } & \multicolumn{4}{|c|}{ Exsmokers } & \multicolumn{4}{|l|}{ Smokers } \\
\hline & $\begin{array}{l}\text { No } \\
\text { symptoms }\end{array}$ & Symptoms & Missing & $\begin{array}{l}\text { Percentage } \\
\text { with } \\
\text { symptoms }\end{array}$ & $\begin{array}{l}\text { No } \\
\text { sympt } \\
\text { oms }\end{array}$ & Symptoms & Missing & $\begin{array}{l}\text { Percentage } \\
\text { with } \\
\text { symptoms }\end{array}$ & $\begin{array}{l}\text { No } \\
\text { symptoms }\end{array}$ & Symptoms & Missing & $\begin{array}{l}\text { Percentage } \\
\text { with } \\
\text { symptoms }\end{array}$ \\
\hline $\begin{array}{l}\text { Cough usually in the } \\
\text { morning during winter }\end{array}$ & 85 & 0 & 11 & 0 & 149 & 9 & 22 & 6 & 89 & 29 & 36 & 25 \\
\hline $\begin{array}{l}\text { Cough usually day or } \\
\text { night during winter }\end{array}$ & 88 & 0 & 8 & 0 & 145 & 4 & 31 & 3 & 85 & 17 & 52 & 17 \\
\hline $\begin{array}{l}\text { Cough most days at least } \\
3 \text { months a year or more } \\
\text { during winter }\end{array}$ & 88 & 0 & 8 & 0 & 147 & 6 & 27 & 4 & 89 & 29 & 36 & 25 \\
\hline $\begin{array}{l}\text { Cough and expectoration } \\
\text { usually in the morning }\end{array}$ & 85 & 2 & 9 & 2 & 136 & 11 & 33 & 7 & 81 & 31 & 42 & 28 \\
\hline $\begin{array}{l}\text { Cough and expectoration } \\
\text { usually day or night in } \\
\text { winter }\end{array}$ & 88 & 2 & 6 & 2 & 143 & 3 & 34 & 2 & 103 & 10 & 41 & 9 \\
\hline $\begin{array}{l}\text { Cough and expectoration } \\
\text { most days } 3 \text { months a } \\
\text { year or more }\end{array}$ & 90 & 2 & 4 & 2 & 148 & 8 & 24 & 5 & 88 & 23 & 43 & 21 \\
\hline $\begin{array}{l}\text { Wheeze or squeaks any } \\
\text { time }\end{array}$ & 71 & 9 & 16 & 11 & 91 & 40 & 49 & 31 & 44 & 64 & 46 & 59 \\
\hline $\begin{array}{l}\text { Wheeze or squeaks any } \\
\text { time connected with a } \\
\text { common cold }\end{array}$ & 80 & 4 & 12 & 5 & 127 & 17 & 36 & 12 & 65 & 37 & 52 & 36 \\
\hline $\begin{array}{l}\text { Wheeze or squeaks any } \\
\text { time unconnected with a } \\
\text { common cold }\end{array}$ & 92 & 0 & 4 & 0 & 147 & 6 & 27 & 4 & 90 & 22 & 42 & 20 \\
\hline $\begin{array}{l}\text { Wheeze or squeaks most } \\
\text { days a year }\end{array}$ & 94 & 0 & 2 & 0 & 170 & 2 & 8 & 1 & 131 & 3 & 20 & 2 \\
\hline $\begin{array}{l}\text { Dyspnoea when walking } \\
\text { fast on the level or } \\
\text { walking up an incline }\end{array}$ & 82 & 1 & 13 & 1 & 118 & 15 & 47 & 11 & 97 & 17 & 40 & 15 \\
\hline $\begin{array}{l}\text { Dyspnoea when walking } \\
\text { on the level at ordinary } \\
\text { pace }\end{array}$ & 92 & 0 & 4 & 0 & 164 & 4 & 12 & 2 & 139 & 0 & 15 & 0 \\
\hline
\end{tabular}

Subjects with missing data are excluded from the percentage calculation. 


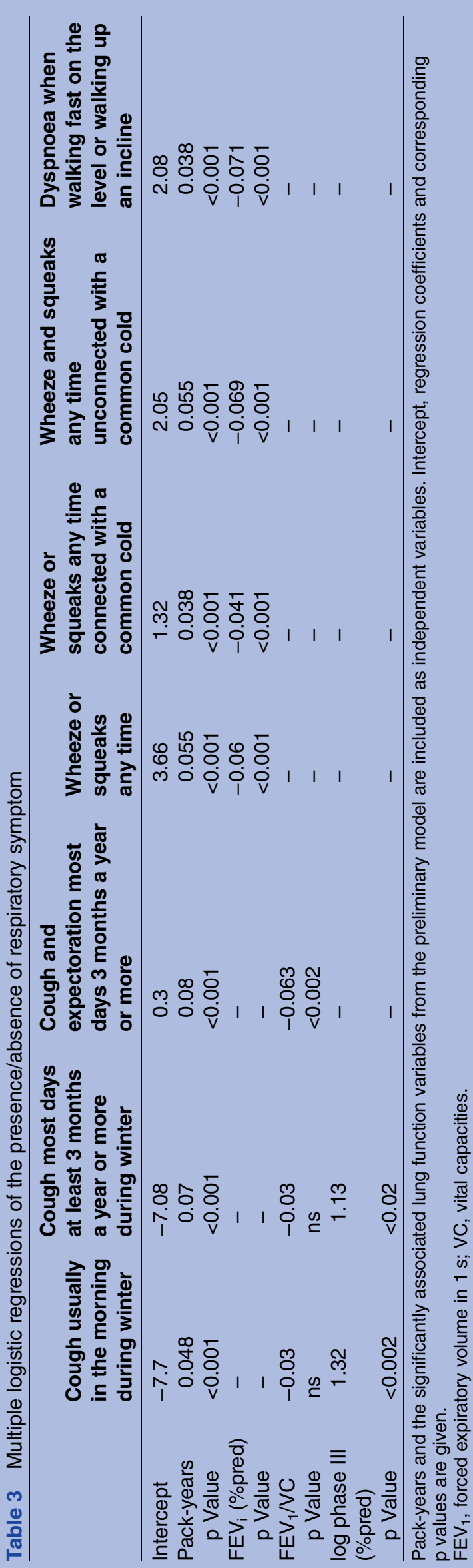

respectively. The sensitivities of the cough symptoms were low but the specificities were relatively high to identify an abnormal/normal slope of phase III. However, 'cough usually in the morning during winter' predicts an abnormal slope of phase III with $92 \%$ probability among smokers $\geq 20$ pack-years and it is about 5 times more likely that someone reporting this symptom has an abnormal slope of phase III compared to someone not reporting this symptom.

Regarding identification of an abnormal $\mathrm{FEV}_{1} / \mathrm{VC}$ ratio the sensitivities were rather similar to that of an abnormal slope of phase III but the specificities and resulting probabilities and likelihood ratios were lower.

\section{DISCUSSION}

The present study shows that: (1) some cough symptoms are significantly associated with the slope of phase III also after allowing for spirometry results and smoking (pack-years); (2) wheeze and dyspnoea are similarly significantly associated with $\mathrm{FEV}_{1}$; (3) smoking normalised slope of phase III is significantly steeper among men reporting respiratory symptoms; (4) some cough symptoms predict an abnormal slope of phase III with $79-92 \%$ probability among smokers ( $\geq 20$ pack-years).

The present material was obtained during 1973 and 1980 in a random population study in Gothenburg, Sweden, of men born in 1913 and 1923. ${ }^{16}{ }^{25}$ The respiratory symptoms were, however, not analysed at the time. Although the material is between 32 and 39 years old there is no apparent reason to question the contemporaneity, as the measurements of lung function would meet modern standards and the questions would be phrased similarly today. Only consistent reports of symptoms and mean values of lung function results from both occasions were considered in the present analysis. This strategy was chosen in order to obtain as reliable data as possible for the statistical analysis. A limitation of this strategy is that missing data are somewhat high (table 2). However, when analysing subjects with missing data for some of the symptoms there were no essential differences compared to subjects who reported symptoms. Some subjects with lung disease are included in the analysis, a quality of a random population sample. For example, 10 subjects reported chronic bronchitis or asthma on both occasions in the present study but information on other diseases is lacking. The definition of smoking habits presented some considerations. Mean values appeared to be impossible to calculate why smoking habits reported 1980 were accepted: Furthermore, if a subject was reported as a smoker in 1973 but non-smoker in 1980 he was considered an exsmoker in 1980. The lack of detailed daily cigarette consumption and the resulting approximation of the calculation of pack-years may furthermore be a limitation.

The prevalence of cough symptoms and dyspnoea among non-smokers, exsmokers and smokers in the present study was lower whereas wheeze was similar 
Table 4 Effects of cough symptoms on the slope of phase III

\begin{tabular}{|c|c|c|c|c|c|c|}
\hline & \multicolumn{6}{|c|}{ Exsmokers and smokers } \\
\hline & \multicolumn{3}{|c|}{ Phase III (\% pred)* } & \multicolumn{3}{|c|}{$\begin{array}{l}\text { Phase III (\% expected, smoking } \\
\text { normalised)* }\end{array}$} \\
\hline & No symptoms & Symptoms & p Value & No symptoms & Symptoms & p Value \\
\hline Cough usually in the morning during winter & 140 & 245 & $<0.001$ & 90 & 139 & $<0.001$ \\
\hline $\begin{array}{l}\text { Cough most days at least } 3 \text { months a year or } \\
\text { more during winter }\end{array}$ & 137 & 238 & $<0.001$ & 90 & 131 & 0.001 \\
\hline
\end{tabular}

compared with the study by Medbö et $a l^{5}$ whereas compared to Sherman et $a l^{26}$ cough prevalence was similar, while wheeze and dyspnoea were more common among smokers. Differences in questionnaires, definitions of symptoms and population samples 5 10 26-28 presumably explain these differences.

Viegi et $a l^{18}$ showed that the slope of phase III of the single-breath $\mathrm{N}_{2}$ test was significantly more abnormal in male smokers with the symptoms cough, phlegm, wheeze and dyspnoea compared to asymptomatic male smokers based on a random population sample drawn from northern Italy. These results are in line with the findings in the present study, and we confirm that the results regarding some cough symptoms are valid also after adjusting for the amount of smoking and spirometric results.

The interpretation of the logistic regression models is complicated by correlations between the slope of phase III, $\mathrm{FEV}_{1}$ and $\mathrm{FEV}_{1} / \mathrm{VC}$. These variables are also biologically interrelated but reflect to a certain extent different parts of the airways and lungs. In a model where pack-years and only one of the lung function variables are included, this lung function variable is significantly related to all the symptoms, illustrating the common information carried by the three lung function variables. Anyhow, cough symptoms may to some extent be an effect of obstruction in peripheral airways whereas wheezes and dyspnoea may to some extent be an effect of obstruction of larger airways, at least among elderly men. This is in line also with the clinical experience that early symptoms in smokers are usually cough with or without expectoration, while wheeze and dyspnoea seem to reflect later stages of more severe respiratory airway and lung damage. Furthermore, when the slope of phase III is normalised for smoking it is still significantly steeper among subjects with cough symptoms compare to those without cough symptoms also (table 4), thus confirming the association between cough symptoms and the slope of phase III.

The ability of respiratory symptoms to predict an abnormal slope of phase III has, to our knowledge, not been reported previously. In the present study 'cough usually in the morning during winter', 'cough most days at least 3 months a year or more during winter' and 'cough and expectoration usually in the morning' could predict an abnormal slope of phase III with a probability of 79-92\% among smokers $\geq 20$ pack-years. The sensitivities were low, however, as only $39-45 \%$ of

Table 5 Diagnostic characteristics of three cough symptoms to detect a normal/abnormal slope of phase III and FEV ${ }_{1} / \mathrm{VC}$ ratio in male smokers with a history of $\geq 20$ pack-years

\begin{tabular}{|c|c|c|c|c|c|c|}
\hline & \multicolumn{2}{|c|}{$\begin{array}{l}\text { Cough usually in the morning } \\
\text { during winter }(n=78)\end{array}$} & \multicolumn{2}{|c|}{$\begin{array}{l}\text { Cough most days at least } \\
3 \text { months a year or more } \\
\text { during winter }(n=77)\end{array}$} & \multicolumn{2}{|c|}{$\begin{array}{l}\text { Cough and expectoration } \\
\text { usually in the morning }(n=70)\end{array}$} \\
\hline & $\begin{array}{l}\text { Phase III >147\% } \\
\text { pred }^{*}\end{array}$ & $\begin{array}{l}\text { FEV }_{1} \text { VC } \\
<0.65\end{array}$ & $\begin{array}{l}\text { Phase III >147\% } \\
\text { pred }^{*}\end{array}$ & $\begin{array}{l}\text { FEV }_{1} / \mathrm{VC} \\
<0.65\end{array}$ & $\begin{array}{l}\text { Phase III >147\% } \\
\text { pred }^{*}\end{array}$ & $\begin{array}{l}\text { FEV }_{1} / \mathrm{VC} \\
<0.65\end{array}$ \\
\hline Sensitivity & 0.42 & 0.44 & 0.39 & 0.42 & 0.45 & 0.42 \\
\hline Specificity & 0.92 & 0.76 & 0.85 & 0.75 & 0.82 & 0.76 \\
\hline $\begin{array}{l}\text { Positive predictive } \\
\text { value }\end{array}$ & 0.92 & 0.5 & 0.83 & 0.46 & 0.79 & 0.46 \\
\hline $\begin{array}{l}\text { Negative predictive } \\
\text { value }\end{array}$ & 0.44 & 0.72 & 0.41 & 0.72 & 0.5 & 0.67 \\
\hline Pretest probability & 0.67 & 0.35 & 0.66 & 0.34 & 0.6 & 0.37 \\
\hline Post-test probability & 0.92 & 0.5 & 0.83 & 0.46 & 0.79 & 0.46 \\
\hline Likelihood ratio & 5.3 & 1.9 & 2.5 & 1.7 & 2.5 & 1.4 \\
\hline
\end{tabular}


subjects with an abnormal slope of phase III had one of the cough symptoms.

Cough receptors in the peripheral airways which seem to be more sensitive in, for example, $\mathrm{COPD}^{29}$ could to some extent explain the association between cough and peripheral airway obstruction as found in the present study.

The knowledge that cough symptoms may indicate smoking-induced peripheral airway obstruction and probably an increased risk of developing $\mathrm{COPD}^{25}$ may provide a useful argument for smoking cessation and when applicable also an argument regarding avoidance of occupational exposure. A clinical follow-up could be worthwhile to consider.

We conclude that, some cough symptoms may be an effect of obstruction in peripheral airways and a predictor of peripheral airways disease at least among male middleaged smokers. Cough-a sound from the silent zone?

Acknowledgements We gratefully acknowledge Dr Joseph Milic-Emili for encouraging us to undertake the present analysis and Alexandra Enocson for valuable technical assistance.

Contributors $\mathrm{JO}$ designed and performed the study, analysed data, wrote the paper, MNT designed the study, wrote the paper, BH designed the study, wrote the paper, BB designed and performed the study, analysed data and wrote the paper.

Funding This study was supported by the Government grant according to the LUA/ALF agreement.

Competing interests None.

Ethics approval This work was performed at the Institution of Medicine at Sahlgrenska Academy, University of Gothenburg, Sweden. The study in 1973 and $1980^{16}{ }^{25}$ was approved by the Committee for Medical Research Ethics at the University of Gothenburg.

Provenance and peer review Not commissioned; externally peer reviewed.

Data sharing statement There are no additional unpublished data from the study.

\section{REFERENCES}

1. Calverley PM, Nordyke RJ, Halbert RJ, et al. Development of a population-based screening questionnaire for COPD. COPD 2005;2:225-32.

2. Hill K, Hodder R, Blouin M, et al. Identifying adults at risk of COPD who need confirmatory spirometry in primary care: do symptom-based questions help? Can Fam Physician 2011;57:e51-7.

3. Lindberg A, Jonsson AC, Ronmark E, et al. Prevalence of chronic obstructive pulmonary disease according to BTS, ERS, GOLD and ATS criteria in relation to doctor's diagnosis, symptoms, age, gender, and smoking habits. Respiration 2005;72:471-9.

4. Martinez FJ, Raczek AE, Seifer FD, et al. Development and initial validation of a self-scored COPD Population Screener Questionnaire (COPD-PS). COPD 2008;5:85-95.

5. Medbo A, Melbye $\mathrm{H}$. What role may symptoms play in the diagnosis of airflow limitation? A study in an elderly population. Scand J Prim Health Care 2008;26:92-8.
6. Mullerova $\mathrm{H}$, Wedzicha J, Soriano JB, et al. Validation of a chronic obstructive pulmonary disease screening questionnaire for population surveys. Respir Med 2004;98:78-83.

7. Ohar JA, Sadeghnejag A, Meyers DA, et al. Do symptoms predict COPD in smokers?. Chest 2010;137:1345-53.

8. Price DB, Tinkelman DG, Nordyke RJ, et al. Scoring system and clinical application of COPD diagnostic questionnaires. Chest 2006;129:1531-9.

9. van Schayck CP, Halbert RJ, Nordyke RJ, et al. Comparison of existing symptom-based questionnaires for identifying COPD in the general practice setting. Respirology 2005;10:323-33.

10. Lindberg A, Eriksson B, Larsson LG, et al. Seven-year cumulative incidence of COPD in an age-stratified general population sample. Chest 2006;129:879-85.

11. Cosio MG, Hale KA, Niewoehner DE. Morphologic and morphometric effects of prolonged cigarette smoking on the small airways. Am Rev Respir Dis 1980;122:265-21.

12. Niewoehner DE, Kleinerman J, Rice DB. Pathologic changes in the peripheral airways of young cigarette smokers. $N$ Engl J Med 1974;291:755-8.

13. Hogg JC, Macklem PT, Thurlbeck WM. Site and nature of airway obstruction in chronic obstructive lung disease. $N$ Engl J Med 1968;278:1355-60.

14. Macklem PT, Mead J. Resistance of central and peripheral airways measured by a retrograde catheter. $J$ Appl Physiol 1967;22:395-401.

15. Cosio M, Ghezzo H, Hogg JC, et al. The relations between structural changes in small airways and pulmonary-function tests. $N$ Engl $J$ Med 1978;298:1277-81.

16. Oxhoj H, Bake B, Wilhelmsen L. Ability of spirometry, flow-volume curves and the nitrogen closing volume test to detect smokers. A population study. Scand J Respir Dis 1977;58:80-96.

17. Petty TL, Silvers GW, Stanford RE, et al. Small airway pathology is related to increased closing capacity and abnormal slope of phase III in excised human lungs. Am Rev Respir Dis 1980;121:449-56.

18. Viegi G, Paoletti P, Di Pede F, et al. Single breath nitrogen test in an epidemiologic survey in North Italy. Reliability, reference values and relationships with symptoms. Chest 1988;93:1213-20.

19. Wilhelmsen L, Tibblin G. Tobacco smoking in fifty-year-old men. I. Respiratory symptoms and ventilatory function tests. Scand $J$ Respir Dis 1966;47:121-30.

20. Olofson J, Bake B, Tengelin MN, et al. COPD 'diagnosis' based on spirometric reference equations. Clin Respir J 2008;2:214-19.

21. Hedenstrom $\mathrm{H}$, Malmberg $\mathrm{P}$, Fridriksson $\mathrm{HV}$. Reference values for lung function tests in men: regression equations with smoking variables. Ups J Med Sci 1986;91:299-310.

22. Oxhoj $\mathrm{H}$, Bake $\mathrm{B}$. Measurement of closing volume with the single breath nitrogen method. Scand J Respir Dis 1974;55:320-31.

23. Sixt R, Bake B, Oxhoj $\mathrm{H}$. The single-breath N2-test and spirometry in healthy non-smoking males. Eur J Respir Dis 1984;65:296-304.

24. Chronic Bronchitis in Great Britain: National Survey Carried Out by the Respiratory Diseases Study Group of the College of General Practitioners. Br Med J 1961;2:973-9.

25. Olofsson J, Bake B, Svardsudd K, et al. The single breath N2-test predicts the rate of decline in FEV1. The study of men born in 1913 and 1923. Eur J Respir Dis 1986;69:46-56.

26. Sherman $\mathrm{CB}, \mathrm{Xu} \mathrm{X}$, Speizer FE, et al. Longitudinal lung function decline in subjects with respiratory symptoms. Am Rev Respir Dis 1992;146:855-9.

27. Krzyzanowski M, Camilli AE, Lebowitz MD. Relationships between pulmonary function and changes in chronic respiratory symptoms. Comparison of Tucson and Cracow longitudinal studies. Chest 1990:98:62-70.

28. Lindberg A, Jonsson AC, Ronmark E, et al. Ten-year cumulative incidence of COPD and risk factors for incident disease in a symptomatic cohort. Chest 2005;127:1544-2.

29. Higenbottam T. Chronic cough and the cough reflex in common lung diseases. Pulm Pharmacol Ther 2002;15:241-7. 